\title{
Perioperative nutrition and enhanced recovery after surgery in gastrointestinal cancer patients. A position paper by the ESSO task force in collaboration with the ERAS society (ERAS coalition)
}

Citation for published version (APA):

Sandrucci, S., Beets, G., Braga, M., Dejong, K., \& Demartines, N. (2018). Perioperative nutrition and enhanced recovery after surgery in gastrointestinal cancer patients. A position paper by the ESSO task force in collaboration with the ERAS society (ERAS coalition). European Journal of Surgical Oncology, 44(4), 509-514. https://doi.org/10.1016/j.ejso.2017.12.010

Document status and date:

Published: 01/04/2018

DOI:

10.1016/j.ejso.2017.12.010

Document Version:

Publisher's PDF, also known as Version of record

\section{Document license:}

Taverne

\section{Please check the document version of this publication:}

- A submitted manuscript is the version of the article upon submission and before peer-review. There can be important differences between the submitted version and the official published version of record. People interested in the research are advised to contact the author for the final version of the publication, or visit the $\mathrm{DOI}$ to the publisher's website.

- The final author version and the galley proof are versions of the publication after peer review.

- The final published version features the final layout of the paper including the volume, issue and page numbers.

Link to publication

\footnotetext{
General rights rights.

- You may freely distribute the URL identifying the publication in the public portal. please follow below link for the End User Agreement:

www.umlib.nl/taverne-license

Take down policy

If you believe that this document breaches copyright please contact us at:

repository@maastrichtuniversity.nl

providing details and we will investigate your claim.
}

Copyright and moral rights for the publications made accessible in the public portal are retained by the authors and/or other copyright owners and it is a condition of accessing publications that users recognise and abide by the legal requirements associated with these

- Users may download and print one copy of any publication from the public portal for the purpose of private study or research.

- You may not further distribute the material or use it for any profit-making activity or commercial gain

If the publication is distributed under the terms of Article 25fa of the Dutch Copyright Act, indicated by the "Taverne" license above,

Download date: 26 Apr. 2023 


\title{
Perioperative nutrition and enhanced recovery after surgery in gastrointestinal cancer patients. A position paper by the ESSO task force in collaboration with the ERAS society (ERAS coalition)
}

\author{
Sergio Sandrucci a, , Geerard Beets ${ }^{\text {b, c }}$, Marco Braga ${ }^{\mathrm{d}}$, Kees Dejong ${ }^{\mathrm{e}, \mathrm{f}}$, \\ Nicolas Demartines ${ }^{g}$ \\ ${ }^{a}$ Visceral Sarcoma Surgery Unit, Città della Salute e della Scienza, Turin, Italy \\ ${ }^{\mathrm{b}}$ The Netherlands Cancer Institute, Amsterdam, The Netherlands \\ ${ }^{c}$ GROW School for Oncology and Developmental Biology, Maastricht University, The Netherlands \\ d San Raffaele University Hospital, Milan, Italy \\ e Department of Surgery, Maastricht University Medical Center, Maastricht, The Netherlands \\ ${ }^{\mathrm{f}}$ Department of Surgery, Uniklinikum Aachen, Aachen, Germany \\ ${ }^{g}$ Department for Visceral Surgery, University Hospital CHUV, Lausanne, Switzerland
}

\section{A R T I C L E I N F O}

\section{Article history:}

Accepted 28 December 2017

Available online 12 January 2018

\section{Keywords:}

Enhanced recovery after surgery

Malnutrition

Frailty

Mini-invasive surgery

Immunonutrition

\begin{abstract}
A B S T R A C $T$
Malnutrition in cancer patients - in both prevalence and degree - depends primarily on tumor stage and site. Preoperative malnutrition in surgical patients is a frequent problem and is associated with prolonged hospital stay, a higher rate of postoperative complications, higher re-admission rates, and a higher incidence of postoperative death. Given the focus on the cancer and its cure, nutrition is often neglected or under-evaluated, and this despite the availability of international guidelines for nutritional care in cancer patients and the evidence that nutritional deterioration negatively affects survival. Inadequate nutritional support for cancer patients should be considered ethically unacceptable; prompt nutritional support must be guaranteed to all cancer patients, as it can have many clinical and economic advantages. Patients undergoing multimodal oncological care are at particular risk of progressive nutritional decline, and it is essential to minimize the nutritional/metabolic impact of oncological treatments and to manage each surgical episode within the context of an enhanced recovery pathway. In Europe, enhanced recovery after surgery (ERAS) and routine nutritional assessment are only partially implemented because of insufficient awareness among health professionals of nutritional problems, a lack of structured collaboration between surgeons and clinical nutrition specialists, old dogmas, and the absence of dedicated resources. Collaboration between opinion leaders dedicated to ERAS from both the European Society of Surgical Oncology (ESSO) and the ERAS Society was born with the aim of promoting nutritional assessment and perioperative nutrition with and without an enhanced recovery program. The goal will be to improve awareness in the surgical oncology community and at institutional level to modify current clinical practice and identify optimal treatment options.
\end{abstract}

๑) 2018 Elsevier Ltd, BASO The Association for Cancer Surgery, and the European Society of Surgical Oncology. All rights reserved.

\section{Introduction}

Malnutrition is a major clinical problem in patients with gastrointestinal malignancy; in surgical patients it is associated with prolonged hospital stay, more postoperative complications,

\footnotetext{
* Corresponding author.

E-mail address: sergio.sandrucci@unito.it (S. Sandrucci).
}

delayed recovery of bowel function, higher re-admission rates, and a higher incidence of postoperative death [1]. Perioperative nutritional support has been introduced in many consensuses and guidelines [2-4], including those from the Enhanced Recovery After Surgery (ERAS) Society for elective colon and rectal surgery $[5,6]$. Considering the negative impact of malnutrition on surgical outcomes in the setting of conventional perioperative care, there is evidence that preoperative nutritional status is a critical determinant of optimal outcomes for gastrointestinal cancer surgery [7]. 
ERAS protocols are multimodal perioperative care pathways designed to achieve early recovery after surgical procedures by maintaining preoperative organ function and reducing the profound stress response following surgery. The key elements of ERAS protocols include preoperative counselling, optimization of nutrition, standardized analgesic and anesthetic regimens, and early mobilization [6]. Despite the significant body of evidence indicating that ERAS protocols lead to improved outcomes, they challenge traditional surgical doctrine, and as a result their implementation has been slow.

The aspect of nutrition is an essential component of enhanced recovery programs, including omission of presurgical fasting, oral carbohydrate load, and early initiation of oral intake after surgery. However, there are no standardized protocols of diet progression before and after oncological surgery. The studies examining the impact of nutritional status on the outcomes of gastrointestinal cancer surgery within an ERAS setting are very heterogeneous, so it is impossible to draw definitive conclusions [8].

The present position paper results from the collaboration between opinion leaders dedicated to ERAS from both the ESSO and ERAS societies. The aim is to emphasize the importance of preoperative nutritional status on the short-term outcomes of an ERAS program for gastrointestinal cancer surgery in order to favor the incorporation of nutritional issues and ERAS philosophy into daily practice. Among the different aspects of perioperative management, the key issues for a best-practice approach for oncology patients undergoing gastrointestinal surgery must be nutrition assessment, management of frailties, prehabilitation, and minimally invasive surgery.

\section{Importance of standard ERAS}

Enhanced recovery is a multimodal perioperative care pathway designed to achieve early recovery by attenuating surgical stress with a significant reduction (30-40\%) in postoperative complications [9]. This is based on more than 20 evidence-based interventions covering all areas of the patients' journey throughout the surgical process [10]. Various terminologies (fast-track, enhanced recovery program) with different protocols have been described in the literature. The ERAS Society [11] was the first to publish international consensus guidelines for colorectal surgery [12], and these were then extended to various other surgeries. The use of standard ERAS as described by the guidelines is essential in order to have a common language worldwide. This allows internal and external reproducibility, as well as comparisons between different centers. Consequently, multicentric studies can be conducted and published [13]. Moreover, a standardized ERAS implementation is also a key element for sustained beneficial results over time [14] Therefore, a well-established and standardized ERAS is essential for evidence-based management of patients.

\section{The need for nutritional screening and supplementation in malnourished patients}

The influence of nutritional status on postoperative morbidity and mortality has been well documented in both retrospective and prospective studies. Inadequate oral intake for more than 14 days is associated with higher mortality. The energy and protein requirements can be estimated at $25-30 \mathrm{kcal} / \mathrm{kg}$ and $1.5 \mathrm{~g} / \mathrm{kg}$ ideal body weight, respectively [3]. Two multivariate analyses have shown, for patients undergoing surgery for cancer, that undernutrition is an independent risk factor for increased complications and mortality, length of hospital stay, and costs $[15,16]$.

The prevalence of malnutrition is in the range $15-60 \%$ in hospitalized patients, and increases up to $71 \%$ in cancer patients [17].
Malnutrition is also related to cachexia and sarcopenia; the pathophysiology of weight loss in these patients may be related to a combination of undernutrition, inflammation, and cancer-induced catabolism [18]. A recent meta-analysis has clearly shown that sarcopenia is an independent prognostic factor for complications and survival following oncological surgery [19]. Identification of malnutrition is especially important for patients with cancer who undergo surgery, being associated with significant catabolic changes including net fat oxidation and lean tissue loss.

Implementation of neoadjuvant chemotherapy as the standard of care for cancer patients represents an additional nutritional concern; in a study of patients with esophageal cancer the rate of malnutrition increased to $22 \%$ after neoadjuvant chemotherapy $(P=.046)[20]$.

Improvement in nutritional status can decrease the infection rate in critically ill patients. In an RCT assessing the effects of parenteral nutrition support in orally undernourished patients, a decrease in nosocomial infections was observed among supported versus not-supported patients $(P=.02)[21]$.

It is essential to minimize the nutritional/metabolic impact of both surgery and multimodal treatments by identifying patients in need of nutritional interventions. The Scored Patient-Generated Subjective Global Assessment (PG-SGA) has been accepted as a malnutrition assessment tool for the oncology population and has been used in many studies [22]; sarcopenia can easily be quantified using preoperative CT scans, and its detection can be used to improve the clinical management of sarcopenic cancer patients [19].

Perioperative care must include nutrition in the overall patient management by optimization of nutritional status prior to surgery, avoiding long periods of preoperative fasting, re-establishing early postoperative oral feeding, and starting nutritional therapy as soon as a nutritional risk becomes apparent. The ERAS protocol follows these principles strictly (preoperative carbohydrate loading, early PO feeding), allowing a significant reduction in length of hospital stay for patients undergoing either minor or major abdominal surgery $[23,24]$.

The role of oral nutritional supplements (ONSs) in malnourished patients is well established; in a recent randomized controlled trial (RCT) patients with colorectal cancer with preoperative weight loss $>1 \mathrm{~kg} / 3-6$ months were randomized to receiving either $250 \mathrm{~mL} /$ day ONS (10.1 $\mathrm{KJ}$ and $0.096 \mathrm{~g}$ protein per $\mathrm{mL}$ ) plus dietary advice or dietary advice alone. Compared with dietary advice alone, ONS patients had fewer infections and lower weight loss after surgery for colorectal cancer [25].

The role of nutritional supplements in well-nourished surgical patients is still debated. In a Polish RCT [26] patients without malnutrition received ONS for 14 days before surgery or (control arm) were kept on their everyday diet. In the postoperative period, patients in the control group had significantly more serious complications $(P<.001)$ compared to patients receiving nutritional supplementation. Moreover, levels of all laboratory parameters declined significantly $(P<.001)$ in these patients, while remaining stable or increasing in the interventional arm (albumin plus total protein or transferrin plus total lymphocyte count, respectively).

A recently published Cochrane review [27] failed to observe any significant benefit of early postoperative enteral feeding in colorectal patients, but the 14 studies analyzed were either small or were poor methodologically.

Patients at moderate or severe nutritional risk (especially those undergoing upper gastrointestinal cancer surgery) should be considered for routine postoperative nutritional support (where relevant by oral or enteral routes) and consideration should be given to extending such support when the patient is discharged into the community $[28,29]$. 


\section{Prehabilitation}

In cancer patients, the impairment of aerobic capacity negatively affects preoperative functional reserve and increases the risk of postoperative complications [30]. Often, these patients have a low muscle mass due to undernutrition and/or cancer-related muscle catabolism. Recent studies suggest that several cytokines produced by the tumor - or secreted by the host in response to the tumor - induce muscle hypercatabolism [31]. Cancer-associated systemic inflammation causes a greater need for glucose as a substrate to support inflammatory tissue and immune cells. Therefore, part of the muscle mass is converted to glucose via gluconeogenesis. As a consequence, there ensues a rapid loss of muscle mass and a decrease in muscle function. In cancer patients, sarcopenia has been associated with a worse physical performance, reduced response to chemoradiotherapy, increased postoperative morbidity and mortality, and a reduced life expectancy [32-36]. Sometimes, low muscle protein availability is associated with an increased visceral adipose tissue resulting in sarcopenic obesity. An excess of visceral fat is a source of pro-inflammatory cytokines and leptin, which influence insulin resistance and energetic metabolism. The combination of visceral obesity and sarcopenia reduces the chance of rescuing patients from major postoperative complications and increases the likelihood of postoperative mortality [37-39].

There is some evidence that optimizing body composition and enhancing oxygen uptake ability before surgery may contribute to improved postoperative outcome. A multimodal prehabilitation program - including physical exercise, nutritional supplements, and anxiety-reduction strategies - can optimize the patient's body composition and physical performance. In a randomized trial, a prehabilitation program enhanced patient functional recovery, reduced postoperative morbidity, and shortened hospital stay following colorectal surgery [40]. Similarly, a personalized prehabilitation program enhanced aerobic capacity and reduced postoperative complications in a randomized blind controlled trial carried out in high-risk patients undergoing major gastrointestinal surgery [41]. Since prehabilitation programs and types of exercise training differed during the intervention (3-6 weeks), future studies should be carried out to standardize the preoperative pathway.

\section{The management of frail and elderly patients}

More and more elderly patients are being surgically treated for cancer; frequently, these patients are frail and need special assessment and care. Within an older population, comorbidities and age-related cachexia and sarcopenia are more prevalent. This may have a negative effect on the patient's fitness and postoperative outcome. Cancer cachexia is associated with a mortality rate of up to $80 \%[18,42]$. Weight loss is the most universal symptom of cancer cachexia. However, weight loss does not specify what is lost; this can be either skeletal muscle or adipose tissue, or both. So, assessing body composition may require detailed assessment by e.g. CT scan or MRI [43]. Of note, edema and tumor load may cause an increase in weight, potentially masking weight loss.

Malabsorption and maldigestion are major drivers of weight loss in patients with pancreatic cancer and therefore also require assessment. Preoperative screening to identify vulnerable patients is essential since every frail and elderly (cachectic) patient presents with specific problems and comorbidities. For these reasons, patients who are at risk of complications should receive additional pre- and postoperative support from a dietitian whenever possible. Moreover, timely intervention in the case of complications is important, potentially reducing sequential complications and complication-related mortality (i.e. reducing "failure to rescue") [44]. Preoperative interventions (e.g. exercise, nutritional support, and pharmacological support) should be developed for vulnerable patients to improve outcome: the "better in, better out" principle.

Nutritional evaluation and its prognostic implications are involved in the very important aspect of assessing treatment goals together with patients. An integral part of the risk assessment, this could be a decision determinant for alternative less-invasive treatment or even no treatment at all.

\section{The role of immunonutrients}

In recent years, standard nutritional formulas have been modified by the addition of arginine, omega- 3 fatty acids, glutamine, and other components, which may increase immune responses by modulating inflammatory responses or enhancing protein synthesis after surgery. The potential effects of immunonutrients include reducing infections and other postoperative complications. Significant benefits regarding infectious complications were found for the pre-, peri- and postoperative use of the immunomodulating diet [45]. The non-infectious complications and the length of hospital stay were reduced in the case of peri- or postoperative initiation of the diet. The meta-analysis from Osland et al. and Song et al. $[45,46]$ confirmed the benefits of the perioperative and sole postoperative use; the superiority of immune-enriched supplements has not been proven in the preoperative period, as no significant differences were found either in the complication rate or in functional capability and body weight.

The SONVI study [47] has shown that the combination of ERAS care and immunonutrient supplements can reduce postoperative complications. Patients receiving immunonutrients preoperatively and postoperatively had fewer complications (primarily infectious) than those who received standard supplements.

Several meta-analyses of randomized controlled studies have shown that patients undergoing major surgery (including for cancer) may have reduced infectious complication rates and lengths of stay in hospital when given an immune-enhancing feed rather than a standard isocaloric, isonitrogenous feed [46,48-51]. However, strong evidence is still lacking. A recent study [52] evaluated the potential benefits of different combinations of immunonutrients in major abdominal surgery on mortality, morbidity and length of hospital stay. A total of 83 RCTs with 7116 patients were evaluated. Taking all trials into account, immunonutrients reduced overall complications and infectious complications, and shortened hospital stay, compared with control groups (grade of evidence low to moderate). These effects vanished after excluding trials at high and unclear risk of bias: non-industry-funded trials reported no positive effects for overall complications, whereas those funded by industry reported large effects. This bias clearly reduces confidence in the existing evidence.

\section{Surgical technique: instrumentation}

In abdominal surgery, laparoscopic techniques decrease the trauma to the abdominal wall and peritoneum, and particularly meticulous technique in the operative field is mandatory. Laparoscopic techniques generally result in less blood loss, a decreased surgical stress response, less postoperative pain and discomfort, earlier return of bowel function, and quicker recovery. Together with the decreased incidence of wound complications, this leads to decreased hospital stay compared to open surgery. The development of laparoscopic techniques had the same goals and ran parallel to the development of the first ERAS protocols, even though those were initially designed for open surgery. It has become clear that incorporation of laparoscopic techniques in ERAS protocols further enhances outcome. This was demonstrated in the four-arm randomized LAFA trial where the combined laparoscopy/fast-track 
arm had a shorter hospital stay than the open and non-fast-track arms [53]. The current evidence suggests that laparoscopic techniques and ERAS protocols work highly synergistically. The decrease in surgical trauma after minimally invasive surgery is one important element in improving recovery after surgery. In open surgery thoracic epidural anesthesia was very important for pain control but is less so with laparoscopic surgery, and many centers have adapted their protocols accordingly [54]. Laparoscopic instrumentation has gradually improved, and high-definition optical systems have improved vision to overcome the difficulties inherent in laparoscopic surgery. There is, however, still room for technical improvement that will allow a wider use of minimally invasive techniques in more surgical areas. The cost issue should also be addressed by the manufacturing companies in order to allow a more global implementation.

In addition to laparoscopic instrumentation, there are also other areas of technical progress that can benefit patients. Surgical navigation and incorporation of perioperative imaging methods can allow for more precise location of tumors or metastases and for more targeted resection or intervention, also decreasing surgical trauma. Anastomotic healing is an important determinant in the outcome of gastrointestinal surgery, and further improvements in stapler design and perfusion assessment could help to decrease anastomotic leaks. A more controversial area of technical progress is robotic surgery, with more degrees of freedom, 3D view, more stability, etc. The exact benefit remains to be established, and the economic aspects will be highly important in determining implementation. In an RTC considering robotic-assisted versus laparoscopic rectal cancer surgery [55], there were neither significant differences in conversion rates to open surgery nor in complication rates and quality-of-life outcomes. The healthcare costs in roboticassisted laparoscopic group were significantly higher than in the laparoscopic group.

In addition to the short-term benefits, the assessment of new technologies also concerns long-term oncological safety. For colon cancer, a Cochrane analysis has convincingly shown that oncological outcomes do not differ between open and laparoscopic approaches [56]. For rectal cancer, oncological equivalence was not clearly demonstrated, and further studies are needed [57,58]. For esophagogastric and pancreatic cancer and liver metastases [59-62] comparative cohort series suggest that, with proper selection, the oncological outcome may not be compromised.

\section{Impact on healthcare costs}

Steady increases in healthcare costs expressed as a proportion of Gross Domestic Product are observed worldwide. Therefore, cost reductions are a key issue in most healthcare systems. It is now well established that successful implementation of ERAS leads not only to an improvement in postoperative outcome but also to a significant reduction in costs, estimated at 1800-8000 Euros per patient $[63,64]$. The sustained implementation of ERAS programs requires additional resources, both clinical (ERAS dedicated nurse, training and dedicated time for the ERAS team and nutrition assessment) and technical (ERAS Interactive Audit System, goal-directed fluid therapy monitoring, carbohydrate drinks, nutritional integration). Taking these costs into account, ERAS is still associated with a positive return on investment (ROI) [65,66]. Direct savings are obtained in decreased resource utilization with reduced laboratory tests and radiological procedures, and mostly in decreased lengths of hospital stays [63]. By multiplying length-of-stay reductions (at least $1-2$ days) $[67,68]$ by annual patient load, the annual impact on inpatient bed-days saved can be estimated for each institution. In conclusion, ERAS program implementation is a powerful tool for decreasing costs, an essential issue in modern health care.

\section{Conclusions}

Malnutrition is particularly common in gastrointestinal surgical oncology and may affect over $50 \%$ of patients. Nutrition is an important component of ERAS, and nutritional status is an independent predictor of clinical outcome. In patient groups within the ERAS program, nutrition recommendations should be properly integrated to achieve optimal perioperative care and to reduce operative risk, especially in malnourished patients.

Preoperative optimization of patients plays an essential role in successful outcomes. Screening for malnutrition and sarcopenia is one of the important elements within a multimodal ERAS program because malnourished patients have worse surgical outcomes, such as increased postoperative morbidities, delayed recovery of gastrointestinal function, and prolonged hospitalization.

The ultimate benefits of minimally invasive surgery and ERAS are improved outcomes and faster recovery, given that laparoscopic surgery has been shown to improve outcomes alone or as a part of ERAS. Today, laparoscopy, where applicable, is considered an integral component of any ERAS protocol.

In Europe, ERAS and routine nutritional assessment are part of common practice in only a minority of cases, or are only partially implemented, with limited advantages for the patients. This could be related to insufficient awareness of nutritional problems among health professionals, lack of structured collaboration between surgeons and clinical nutrition specialists, old dogmas, and the absence of dedicated resources. In view of the above considerations, nutritional support and ERAS pathways may still represent a neglected right for cancer patients. This issue is particularly disturbing as robust supporting scientific evidence is available.

\section{Conflict of interest statement}

No conflict of interest of the involved authors concerning this paper.

\section{Aknowledgements}

This manuscript was prepared with scientific support from EFADs, European Specialist Dietetic Network for Oncology http:// www.efad.org/everyone.

\section{References}

[1] Cid Conde L, Fernandez Lopez T, Neira Blanco P, Arias Delgado J, Varela Correa J, Gomez Lorenzo F. Hyponutrition prevalence among patients with digestive neoplasm before surgery. Nutr Hosp 2008;23:46-53.

[2] Arends J, Baracos V, Bertz H, Bozzetti F, Calder PC, Deutz NEP, et al. ESPEN expert group recommendations for action against cancer-related malnutrition. Clin Nutr 2017 Oct;36(5):1187-96.

[3] Arends J, Bachmann P, Baracos V, Barthelemy N, Bertz H, Bozzetti F, et al. ESPEN guidelines on nutrition in cancer patients. Clin Nutr 2017 Feb;36(1): $11-48$.

[4] Weimann A, Braga M, Carli F, Higashiguchi T, Hübner M, Klek S, et al. ESPEN guideline: clinical nutrition in surgery. Clin Nutr 2017 Jun;36(3):623-50.

[5] Gustafsson UO, Scott MJ, Schwenk W, Demartines N, Roulin D, Francis N, et al., Enhanced Recovery After Surgery (ERAS) Society for Perioperative Care; European Society for Clinical Nutrition and Metabolism (ESPEN); International Association for Surgical Metabolism and Nutrition (IASMEN). Guidelines for perioperative care in elective colonic surgery: enhanced recovery after surgery (ERAS( $(\mathbb{R})$ ) society recommendations. World J Surg 2013 Feb;37(2): 259-84.

[6] Nygren J, Thacker J, Carli F, Fearon KC, Norderval S, Lobo DN, et al., Enhanced Recovery After Surgery Society. Guidelines for perioperative care in elective rectal/pelvic surgery: enhanced recovery after surgery (ERAS $\left.{ }^{\circledR}\right)$ society recommendations. Clin Nutr 2012 Dec;31(6):801-16.

[7] Sungurtekin H, Sungurtekin U, Balci C, Zencir M, Erdem E. The influence of nutritional status on complications after major intraabdominal surgery. J Am Coll Nutr 2004 Jun;23(3):227-32.

[8] Gustafsson UO, Ljungqvist O. Perioperative nutritional management in digestive tract surgery. Curr Opin Clin Nutr Metab Care 2011;14:504-9. 
[9] Bond-Smith G, Belgaumkar AP, Davidson BR, Gurusamy KS. Enhanced recovery protocols for major upper gastrointestinal, liver and pancreatic surgery. Cochrane Database Syst Rev 2016;2. CD011382.

[10] Ljungqvist O, Scott M, Fearon KC. Enhanced recovery after surgery: a review. JAMA Surg 2017;152(3):292-8.

[11] Ljungqvist O, Young-Fadok T, Demartines N. The history of enhanced recovery after surgery and the ERAS society. J Laparoendosc Adv Surg Tech A 2017;27(9):860-2.

[12] Fearon KC, Ljungqvist $\mathrm{O}$, Von Meyenfeldt $\mathrm{M}$, Revhaug A, Dejong $\mathrm{CH}$, Lassen K, et al. Enhanced recovery after surgery: a consensus review of clinical care for patients undergoing colonic resection. Clin Nutr 2005;24(3): 466-77.

[13] ERAS Compliance Group. The impact of enhanced recovery protocol compliance on elective colorectal cancer resection: results from an international registry. Ann Surg 2015 Jun;261(6):1153-9.

[14] Martin D, Roulin D, Addor V, Blanc C, Demartines N, Hubner M. Enhanced recovery implementation in colorectal surgery-temporary or persistent improvement? Langenbeck's Arch Surg 2016;401(8):1163-9.

[15] Leandro-Merhi VA, de Aquino JL. Determinants of malnutrition and postoperative complications in hospitalized surgical patients. J Health Popul Nutr 2014 Sep;32(3):400-10.

[16] Shpata V, Prendushi X, Kreka M, Kola I, Kurti F, Ohri I. Malnutrition at the time of surgery affects negatively the clinical outcome of critically ill patients with gastrointestinal cancer. Med Arch 2014 Aug;68(4):263-7.

[17] Lim SL, Ong KC, Chan YH, Loke WC, Ferguson M, Daniels L. Malnutrition and its impact on cost of hospitalization, length of stay, readmission and 3-year mortality. Clin Nutr 2012 Jun;31(3):345-50.

[18] Fearon K, Strasser F, Anker SD, Bosaeus I, Bruera E, Fainsinger RL, et al. Definition and classification of cancer cachexia: an international consensus. Lancet Oncol 2011 May;12(5):489-95.

[19] Joglekar S, Nau PN, Mezhir JJ. The impact of sarcopenia on survival and complications in surgical oncology: a review of the current literature. J Surg Oncol 2015 Oct;112(5):503-9.

[20] Awad S, Tan BH, Cui H, Bhalla A, Fearon KC, Parsons SL, et al. Marked changes in body composition following neoadjuvant chemotherapy for oesophagogastric cancer. Clin Nutr 2012 Feb;31(1):74-7.

[21] Heidegger CP, Berger MM, Graf S, Zingg W, Darmon P, Costanza MC, et al Optimisation of energy provision with supplemental parenteral nutrition in critically ill patients: a randomised controlled clinical trial. Lancet 2013 Feb 2;381(9864):385-93.

[22] Cunha Cde M, Sampaio Ede J, Varjão ML, Factum CS, Ramos LB, BarretoMedeiros JM. Nutritional assessment in surgical oncology patients: a comparative analysis between methods. Nutr Hosp 2014 Nov 1;31(2): 916-21.

[23] Awad S, Varadhan KK, Ljungqvist O, Lobo DN. A meta-analysis of randomised controlled trials on preoperative oral carbohydrate treatment in elective surgery. Clin Nutr 2013;32:34-44.

[24] Smith MD, McCall J, Plank L, Herbison GP, Soop M, Nygren J. Preoperative carbohydrate treatment for enhancing recovery after elective surgery. Cochrane Database Syst Rev 2014 Aug 14;8.

[25] Burden ST, Gibson DJ, Lal S, Hill J, Pilling M, Soop M, et al. Pre-operative oral nutritional supplementation with dietary advice versus dietary advice alone in weight-losing patients with colorectal cancer: single-blind randomized controlled trial. J Cachexia Sarcopenia Muscle 2017 Jun;8(3): 437-46.

[26] Kabata P, Jastrzębski T, Kąkol M, Król K, Bobowicz M, Kosowska A, et al. Preoperative nutritional support in cancer patients with no clinical signs of malnutrition-prospective randomized controlled trial. Support Care Cancer 2015 Feb;23(2):365-70.

[27] Andersen HK, Lewis SJ, Thomas S. Early enteral nutrition within $24 \mathrm{~h}$ of colorectal surgery versus later commencement of feeding for postoperative complications. Cochrane Database Syst Rev 2006;4. CD004080.

[28] Beattie AH, Prach AT, Baxter JP, Pennington CR. A randomised controlled trial evaluating the use of enteral nutritional supplements postoperatively in malnourished surgical patients. Gut 2000;46:813-8.

[29] Vidal Casariego A, Calleja Fernández A, Villar Taibo R, Urioste Fondo A, Pintor de la Maza B, Hernández Moreno A, et al. Efficacy of enteral nutritional sup port after hospital discharge in major gastrointestinal surgery patients: a systematic review. Nutr Hosp 2017 Jun 5;34(3):719-26.

[30] Snowden CP, Prentis J, Jacques B, Anderson H, Manas D, Jones D, et al. Cardiorespiratory fitness predicts mortality and hospital length of stay after major elective surgery in older people. Ann Surg 2013 Jun;257(6):999-1004.

[31] Tan CR, Yaffee PM, Jamil LH, Lo SK, Nissen N, Pandol SJ, et al. Pancreatic cancer cachexia: a review of mechanisms and therapeutics. Front Physiol 2014:83-8.

[32] Reisinger KW, van Vugt JL, Tegels JJ, Snijders C, Hulsewé KW, Hoofwijk AG, et al. Functional compromise reflected by sarcopenia, frailty, and nutritiona depletion predicts adverse postoperative outcome after colorectal cancer surgery. Ann Surg 2015;261:345-52.

[33] Malietzis G, Aziz O, Bagnall NM, Johns N. The role of body composition evaluation by computerized tomography in determining colorectal cancer treatment outcomes: a systematic review. Eur J Surg Oncol 2015;41(2): 186-96.

[34] Lieffers JR, Bathe OF, Fassbender K, Winget M, Baracos VE. Sarcopenia is associated with postoperative infection and delayed recovery from colorectal cancer resection surgery. Br J Cancer 2012;107(6):931-6.
[35] Peng PD, van Vledder MG, Tsai S, de Jong MC, Makary M, Ng J, et al. Sarcopenia negatively impacts short-term outcomes in patients undergoing hepatic resection for colorectal liver metastasis. HPB (Oxford) 2011;13(7):439-46.

[36] Bachmann J, Heiligensetzer M, Krakowski-Roosen H, Büchler MW, Friess H, Martignoni ME. Cachexia worsens prognosis in patients with resectable pancreatic cancer. J Gastrointest Surg 2008 Jul;12(7):1193-201.

[37] Pausch T, Hartwig W, Hinz U, Swolana T, Bundy BD, Hackert T, et al. Cachexia but not obesity worsens the postoperative outcome after pancreatoduodenectomy in pancreatic cancer. Surgery 2012 Sep;152(3 Suppl1):S81-8.

[38] Peng P, Hyder O, Firoozmand A, Kneuertz P, Schulick RD, Huang D, et al. Impact of sarcopenia on outcomes following resection of pancreatic adenocarcinoma. J Gastrointest Surg 2012 Aug;16(8):1478-86.

[39] Pecorelli N, Carrara G, De Cobelli F, Cristel G, Damascelli A, Balzano G, et al. Effect of sarcopenia and visceral obesity on mortality and pancreatic fistula following pancreatic cancer surgery. Br J Surg 2016 Mar;103(4):434-42.

[40] Carli F, Charlebois P, Stein B, Feldman L, Zavorsky G, Kim DJ, et al. Randomized clinical trial of prehabilitation in colorectal surgery. Br J Surg 2010 Aug;97(8): 1187-97.

[41] Barberan-Garcia A, Ubré M, Roca J, Lacy AM, Burgos F, Risco R, et al. Personalised prehabilitation in high-risk patients undergoing elective major abdominal surgery: a randomized blinded controlled trial. Ann Surg 2018 Jan;267(1):50-6.

[42] Von Haehling S, Anker SD. Prevalence, incidence and clinical impact of cachexia: facts and numbers-update 2014. J Cachexia Sarcopenia Muscle 2014;5(4):261-3.

[43] Mourtzakis M, Prado CMM, Lieffers JR, Reiman T, McCargar LJ, Baracos VE. A practical and precise approach to quantification of body composition in cancer patients using computed tomography images acquired during routine care. Appl Physiol Nutr Metab 2008;33(5):997-1006.

[44] Taenzer AH, Pyke JB, McGrath SP. A review of current and emerging approaches to address failure-to-rescue. Anesthesiology 2011;115(2):421-31.

[45] Song GM, Tian X, Zhang L, Ou YX, Yi LJ, Shuai T, et al. Immunonutrition support for patients undergoing surgery for gastrointestinal malignancy: preoperative, postoperative, or perioperative? A bayesian network metaanalysis of randomized controlled trials. Medicine (Baltimore) 2015 Jul;94(29):e1225.

[46] Osland E, Hossain MB, Khan S, Memon MA. Effect of timing of pharmaconutrition (immunonutrition) administration on outcomes of elective surgery for gastrointestinal malignancies: a systematic review and meta-analysis. JPEN J Parenter Enter Nutr 2014 Jan;38(1):53-69.

[47] Moya P, Soriano-Irigaray L, Ramirez JM, Garcea A, Blasco O, Blanco FJ, et al. Perioperative standard oral nutrition supplements versus immunonutrition in patients undergoing colorectal resection inan enhanced recovery (eras) protocol: a multicenter randomized clinical trial (SONVI study). Medicine (Baltimore) 2016 May;95(21):e3704.

[48] Hegazi RA, Hustead DS, Evans DC. Preoperative standard oral nutrition supplements vs immunonutrition: results of a systematic review and metaanalysis. J Am Coll Surg 2014:219:1078-87.

[49] Braga M, Wischmeyer PE, Drover J, Heyland DK. Clinical evidence for pharmaconutrition in major elective surgery. J Parenter Enteral Nutr 2013;37(5 Suppl.):66S-72S.

[50] Hübner M, Cerantola Y, Grass F, Bertrand PC, Schäfer M, Demartines N. Preoperative immunonutrition in patients at nutritional risk: results of a doubleblinded randomized clinical trial. Eur J Clin Nutr 2012 Jul;66(7):850-5.

[51] Marimuthu K, Varadhan KK, Ljungqvist O, Lobo DN. A meta-analysis of the effect of combinations of immune modulating nutrients on outcome in patients undergoing major open gastrointestinal surgery. Ann Surg 2012;255(6): 1060-8.

[52] Probst P, Ohmann S, Klaiber U, Hüttner FJ, Billeter AT, Ulrich A, et al. Metaanalysis of immunonutrition in major abdominal surgery. Br J Surg 2017 Nov;104(12):1594-608.

[53] Vlug MS, Wind J, Hollmann MW, Ubbink DT, Cense HA, Engel AF, et al., LAFA study group. Laparoscopy in combination with fast track multimodal management is the best perioperative strategy in patients undergoing colonic surgery: a randomized clinical trial (LAFA-study). Ann Surg 2011 Dec;254(6): 868-75

[54] Feldheiser A, Aziz O, Baldini G, Cox BP, Fearon KC, Feldman LS, et al. Enhanced recovery after surgery (ERAS) for gastrointestinal surgery, part 2: consensus statement for anaesthesia practice. Acta Anaesthesiol Scand 2016 Mar;60(3): 289-334.

[55] Jayne D, Pigazzi A, Marshall H, Croft J, Corrigan N, Copeland J, et al. Effect of robotic-assisted vs conventional laparoscopic surgery on risk of conversion to open laparotomy among patients undergoing resection for rectal cancer: the ROLARR randomized clinical trial. JAMA 2017 Oct 24;318(16):1569-80.

[56] Kuhry E, Schwenk WF, Gaupset R, Romild U, Bonjer HJ. Long-term results of laparoscopic colorectal cancer resection. Cochrane Database Syst Rev 2008 Apr 16;(2). CD003432.

[57] Vennix S, Pelzers L, Bouvy N, Beets GL, Pierie JP, Wiggers T, et al. Laparoscopic versus open total mesorectal excision for rectal cancer. Cochrane Database Syst Rev 2014 Apr 15;(4), CD005200.

[58] Tou S, Bergamaschi R. Laparoscopic rectal cancer resection: inferior to open or not? Colorectal Dis 2016 Mar;18(3):233.

[59] Benedix F, Dalicho SF, Stübs P, Schubert D, Bruns C. Evidence base for minimally invasive esophagectomy for esophageal cancer. Chirurg 2014 Aug;85(8):668-74. 
[60] van der Wielen N, Straatman J, Cuesta MA, Daams F, van der Peet DL. Shortterm outcomes in minimally invasive versus open gastrectomy: the differences between East and West. A systematic review of the literature. Gastric Cancer 2018 Jan;21(1):19-30.

[61] Cesaretti M, Bifulco L, Costi R, Zarzavadjian Le Bian A. Pancreatic resection in the era of laparoscopy: state of art. A systematic review. Int J Surg 2017 Aug;44:309-16.

[62] Okuno M, Goumard C, Mizuno T, Omichi K, Tzeng CD, Chun YS, et al. Operative and short-term oncologic outcomes of laparoscopic versus open liver resection for colorectal liver metastases located in the posterosuperior liver: a propensity score matching analysis. Surg Endosc 2017 Sep 15. https://doi.org/ 10.1007/s00464-017-5861-X.

[63] Roulin D, Donadini A, Gander S, Griesser AC, Blanc C, Hubner M, et al. Costeffectiveness of the implementation of an enhanced recovery protocol for colorectal surgery. Br J Surg 2013;100(8):1108-14.
[64] Joliat GR, Labgaa I, Hubner M, Blanc C, Griesser AC, Schafer M, et al. Costbenefit analysis of the implementation of an enhanced recovery program in liver surgery. World J Surg 2016;40(10):2441-50.

[65] Roulin D, Najjar P, Demartines N. Enhanced recovery after surgery implementation: from planning to success. J Laparoendosc Adv Surg Tech A 2017;27(9):876-9.

[66] Lee L, Li C, Landry T, Latimer E, Carli F, Fried GM, et al. A systematic review of economic evaluations of enhanced recovery pathways for colorectal surgery. Ann Surg 2014;259(4):670-6.

[67] Nicholson A, Lowe MC, Parker J, Lewis SR, Alderson P, Smith AF. Systematic review and meta-analysis of enhanced recovery programmes in surgical patients. Br J Surg 2014;101(3):172-88.

[68] Visioni A, Shah R, Gabriel E, Attwood K, Kukar M, Nurkin S. Enhanced recovery after surgery for non colorectal surgery? A systematic review and metaanalysis of major abdominal surgery. Ann Surg 2018 Jan;267(1):57-65. 